\title{
Effect of Viscosity of an Oil Environment on Fatigue Crack Growth Rate in AISI 316 Stainless Steel
}

K. BAE and H. CONRAD

Materials Science and Engineering Department, North Carolina State University, Raleigh, NC 27695-7907, USA

\section{ABSTRACT}

The effect of viscosity in the range of $10-101500 \mathrm{cS}$ on fatigue crack growth rate, FCGR, ( $\triangle \mathrm{K}$ $=11-25 \mathrm{MPa} \sqrt{\mathrm{m}}$ ) in 316 stainless steel tested in silicone oil was investigated and compared with FCGR, nor on the crack opening load $P_{\text {op }}$. The FCGR and $P_{\text {op }}$ were smaller in the oils than in air for $\Delta \mathrm{K}<\sim 18 \mathrm{MPa} \sqrt{\mathrm{m}}$, but no difference occurred at larger $\Delta \mathrm{K}$ values. Microscopy observations revealed more zig-zags in the crack path for the air environment compared to the oils; also, cleavage facets on the fracture surface and debris along the crack path occurred in air but not in the oils. It is concluded that the observed difference between FCGR in the oils compared to air results mainly from shielding by the oil of the crack tip against chemical reactions.

\section{KEYWORDS}

Fatigue; crack growth; closure; environment; viscosity; zig-zags; cleavage facets; debris.

\section{INTRODUCTION}

It is well known that the fatigue behavior of metals may be influenced by an oil environment. It is wes (Endo et al. 1972, Endo et al., 1972, Frost, 1964, Polk et al., 1975, Ryder et al. Studies (Endo et al., 19) on several alloys have shown that Stage II fatigue crack growth rate

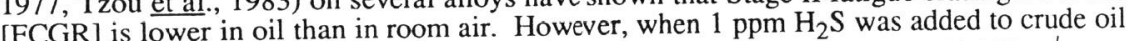
the FCGR in pipeline steels was higher at stress intensity fractor $\Delta \mathrm{K}$ above $20 \mathrm{MPa} \sqrt{\mathrm{m}}$ and the FCGR lower at $\Delta \mathrm{K}$ below $20 \mathrm{M}$ interaction with freshly exposed crack tip was suggested to be al., 1982). Hydrogen in responsible for the ace FC. A reduced FCGR in a coal slurry- $\mathrm{H}_{2}$ environment compared to the on 2 1/4 Cr-1 Mo steel (Woods et al., 1980). This was $\mathrm{H}_{2}$ alone was full effects of the attributed to the shielding of the crack tip by the cor In similar study on $21 / 4 \mathrm{Cr}-1$ Mo steel and 347 stainless steel (McCabe et al., 1980), sulfide corrosion products wedged the crack and 347 stainless steel (McCabe et al. 
In addition to influencing FCGR by shielding the crack tip from air, oils may exert a hydrodynamic wedging action (Endo et al., 1972, Endo et al., 1972, Tzou et s ma exert et al., 1985, Way et al., 1935), the degree of which depends on the viscosity. Fluid peneration into the crack forms a wedge and thereby modifies the effective stress amplitude proposed a consequently the FCGR. Tzou et al. (1985) recently treated the kimprehensive mathenatical model for viscosity-induced crack closure, whic pressure ditribution of $1 / 4$ C -1 Mo steel in the vic. To interpret the complex fatigue crack growth behavior of 2 incorporated into the thriens of environments influence FCGR mutually competitive mechanisms by which viscous oi corrosion-product-induced crack closure and

steel, since this alloy along is the effect of oil viscosity on the FCGR in AISI 316 stainles component in oil refinery and coal 2 conversion systems

\section{EXPERIMENTAL}

The type 316 stainless steel plate $(25.4 \mathrm{~mm}$ thickness) employed in this study had the composition given in Table 1 . As-received plate, which was solution in Table 1. Chemical composition of 316 stainless steel plate (25.4
mm thick) in wt.\%

\begin{tabular}{lllll}
\hline Cr 17.15 & Mo 2.34 & S 0.018 & C 0.059 \\
Ni 13.40 & Si 0.58 & Cu 0.10 & N 0.032 \\
Mn 1.84 & P 0.024 & Co 0.02 & & \\
\hline
\end{tabular}

linear intercept grain size of $90 \mu \mathrm{m}$ and the tensile properties listed in Table 2. CT specimens, conforming to ASTM E-399 with width $35.6 \mathrm{~mm}$ and thickness $3.4 \mathrm{~mm}$ were machined frem the as-received plate to give a Th crack growth orientation. Fatigue crack growth test wom conducted at a constant load amplitude with half sine-wave form $(\mathrm{R}=0.05)$ arowth tests were

Table 2. Grain size and mechanical properties in monotonic loading of 316 stainless steel (1).

\begin{tabular}{|c|c|c|c|c|}
\hline $\begin{array}{l}\text { Grain Size } \\
\quad(\mathrm{mm})\end{array}$ & $\begin{array}{l}\text { Y.S. }(0.2 \%) \\
\quad(\mathrm{MPa})\end{array}$ & $\begin{array}{l}\text { T.S. } \\
\text { (MPa) }\end{array}$ & $\begin{array}{c}\mathrm{El} .(2) \\
(\%)\end{array}$ & $\begin{array}{l}\text { R.A. } \\
(\%)\end{array}$ \\
\hline 92 & 245 & 542 & $82(19 \mathrm{~mm})$ & 69 \\
\hline \multicolumn{2}{|c|}{$\begin{array}{l}\text { Young's Modulus( } 3 \text { ) } \\
\quad(\mathrm{GPa})\end{array}$} & $\begin{array}{c}\text { Hardness }{ }^{(4)} \\
\text { VHN }\left(\mathrm{Kg} / \mathrm{mm}^{2}\right)\end{array}$ & & \\
\hline 193 & \multicolumn{2}{|c|}{216} & & \\
\hline \multicolumn{5}{|c|}{$\begin{array}{l}\text { Notes: } \\
\text { (1) As-received material. } \\
\text { (2) Number in parentheses is gage length. } \\
\text { (3) Value of Youngs Modulus was obtained from ASM Metals Handbook, } \\
\text { 8th Edition, Vol. I (1961) p. 423. } \\
\text { (4) Vickers microharcness (100 g load) }\end{array}$} \\
\hline
\end{tabular}

$\mathrm{Hz}$ in a LFE-150 fatigue machine with its main loading frame in the horizontal position to permit immersion of the specimen in oil environments. A precrack was obtained by the loa shedding technique (ASTME-647, Amzallag et al., 1981), until the

Crack growth tests were performed in: (a) room air (usually $40 \%$ to $60 \%$ relative humidity) as Crack growe a referense it was (bonsidered to be relatively inert. Crack closure was determined from a plot of bead (P) versus crack mouth opening displacement (CMOD), which was measured using a clip (MTS model 632.01) attached to the specimen mouth. Following the method of Carter et gage (M84), the crack opening load $\mathrm{P}_{\mathrm{op}}$ was taken when a change in compliance occurred Coptical and scanning electron microscopy (SEM).

\section{RESULTS}

Plots of $\mathrm{da} / \mathrm{dN}$ versus $\Delta \mathrm{K}$ for silicone oil environments of 10,350 and $101500 \mathrm{cS}$ along with that for room air are presented in Fig. 1. Evident is that the viscosity of the silicone oil in the

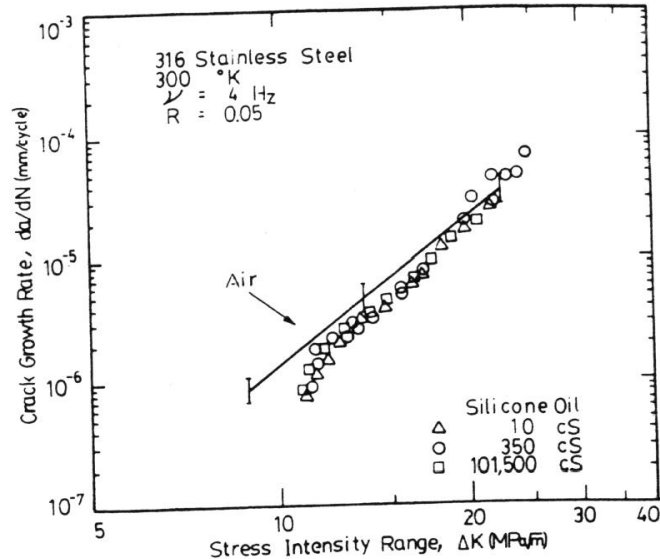

Fig. 1. Effect of the viscosity of silicone oil on fatigue crack growth rate in 316 stainless steel.

range of 10 to $101500 \mathrm{cS}$ does not have a clearly defined effect on the FCGR for the $\Delta \mathrm{K}$ range range of 10 to However, FCGR in the silicone oils is noticeably lower than in air at $\Delta \mathrm{K}<\sim 18$ MPa $\sqrt{ }$, whereas at higher $\triangle \mathrm{K}$ the FCGR in the oils is within the scatter of that in air.

Typical load versus CMOD hysteresis loops and the procedure employed to obtain the crack opening load $\mathrm{P}_{\mathrm{op}}$ are shown in Fig. 2. The variation of $\mathrm{P}_{\mathrm{op}} / \mathrm{P}_{\max }$ with $\Delta \mathrm{K}$ as a function of oil veniscosity is presented along with that for room air in Fig. 3. The viscosity of the silicone oil viscosity is presented a lofect on the $\mathrm{P}_{\mathrm{op}} / \mathrm{P}_{\max }$ ratio. On the other hand, the $\mathrm{P}_{\mathrm{op}} / \mathrm{P}_{\max }$ ratio is oes higher for air than the load $\mathrm{P}$ at a given $\Delta \mathrm{K}$ generally yields a lower FCGR, which is opposite to what was observed here (see. Fig. 1).

The nature of the crack path for 316 stainless steel tested in ambient air and silicone oil (350 The nature of tin 4 and 5 , respectively. Small scale zig-zags, in association with coarse 


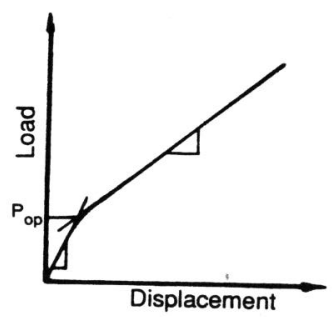

(a)

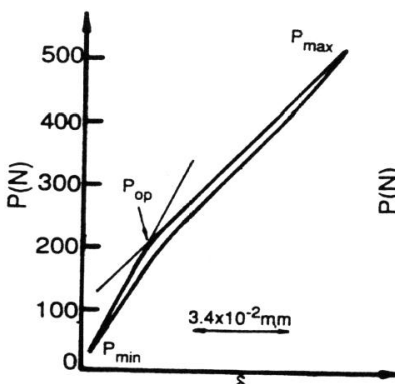

(b)

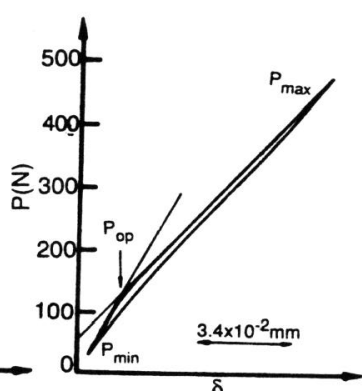

(c)

Fig. 2. Measurements of crack closure: (a) schematic of the method for determinng the crack opening load, $\mathrm{P}_{\mathrm{op}}$, (b) actual load versus displacement diagram in air at $\Delta \mathrm{K}=11.4 \mathrm{MPa} \sqrt{\mathrm{m}}_{\mathrm{m}}$ and (c) actual load versus displacement diagram in silicone oil ( 350 cS) at $\Delta \mathrm{K}=11.3 \mathrm{MPa} \sqrt{\mathrm{m}}$

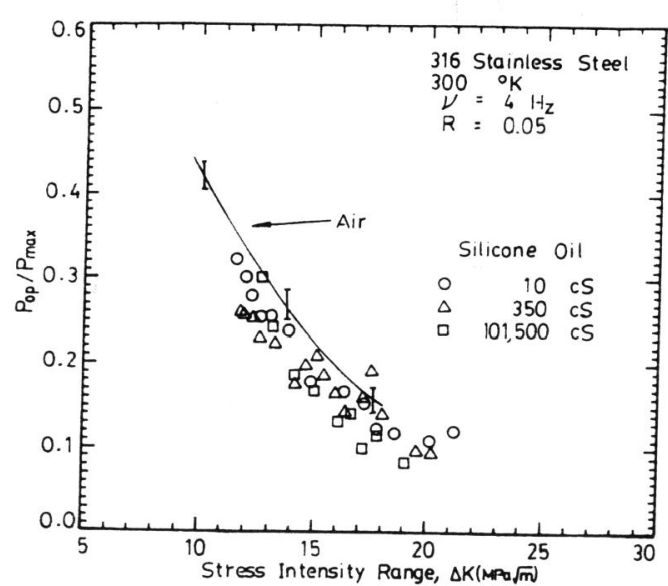

Fig. 3. $\mathrm{P}_{\mathrm{op}} / \mathrm{P}_{\max }$ versus $\Delta \mathrm{K}$ for 316 stainless steel as a function of the viscosity of silicone oil.
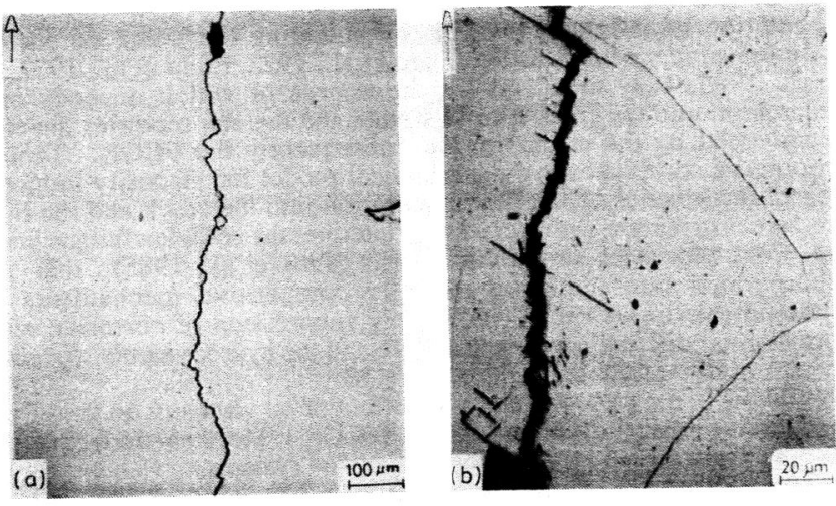

path in 316 stainless steel in air at $\Delta \mathrm{K}$ of (a) $12.3 \mathrm{MPa} \sqrt{\mathrm{m}}$ and (b) $12.7 \mathrm{MPa} \sqrt{\mathrm{m}}$ (after etching). Atrow indicates crack growtide of the micrograph.

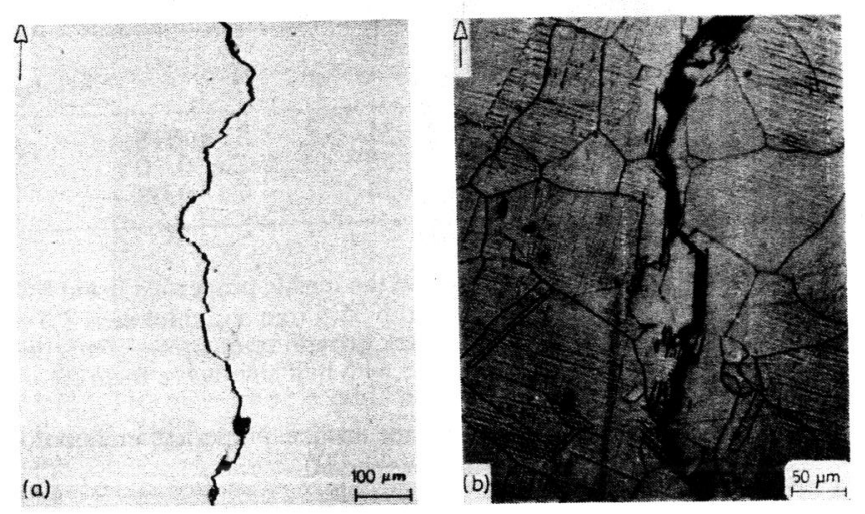

Fig.5. Nature of fatigue crack path in 316 stainless steel in silicone oil $(350 \mathrm{cS}$ ) at $\Delta \mathrm{K}$ of (a) $12.2 \mathrm{MPa} \sqrt{\mathrm{m}}$ and (b) $12.0 \mathrm{MPa} \sqrt{\mathrm{m}}$ (after etching).

(1ip bands, slip bands, occur more frequenty in the specim cycled in air. The debris wally wiped debris observed along the crack on the specim $\mathrm{Fig}$ 6-c. The amount of debris along the crack away with a sot present on specimens cycled in the silicone becam

Typical appearance of the fracture surfaces of specimens fatigued in the silicone oils is shown Th direction. The fracture surfaces of specimens cycled in air (Fig. 8) contained a significant directiont of isolated cleavage facets as well as the fan- and step-patterened surface shown in Fig. 7. The mean size of the facets was the order of the grain size. River-patterened parallel bands 


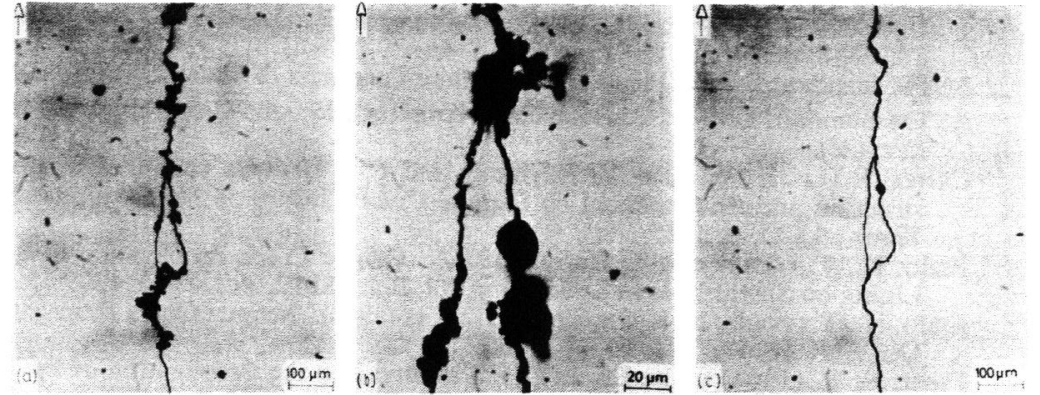

Fig. 6. Debris along fatigue crack in 316 stainless steel cycled in air at $\Delta \mathrm{K}=10 \mathrm{MPa} \mathrm{m}$ (a) immediately following cycling, (b)
higher magnification and (c) after wiping with tissue paper.

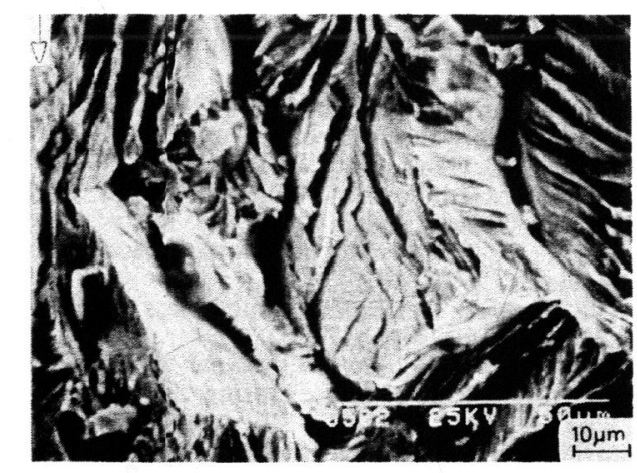

Fig. 7. SEM micrograph of the fracture surface of a specimen tested in silicone oil $(350 \mathrm{cS})$ with $\Delta \mathrm{K}=12 \mathrm{MPa} \sqrt{\mathrm{m}}$

presumably resulting from the second-order slip, are clearly seen on the facets. Also to be noted in Figs. 7 and $8 \mathrm{~d}$ are flattened areas associated with physical contact (considered to give surface-roughness-induced closure)

\section{DISCUSSION}

A four-orders of magnitude variation in the viscosity of the silicone oil had no detectable effect on the FCGR in type 316 stainless steel. This behavior differs from that reported by Tzou et
al. (1985) for tests on bainitic $21 / 4 \mathrm{Cr}-1$ Mo steel. They found that FCGR in inert oils increased in the order of their viscosity and attributed this to viscosity-induced hydrodynamic wedging action on crack closure. The present crack closure results indicate an essentially constant level of crack closure in the silicone oils, which ranged in viscosity from 10 to 101 , $500 \mathrm{cS}$. Worthy of mention in this regard is that the hydrodynamic wedging mechanism is generally regarded less potent compared to other closure sources, such as corrosion debris and fracture surface roughness, in influencing the FCGR (Tzou et al., 1985).
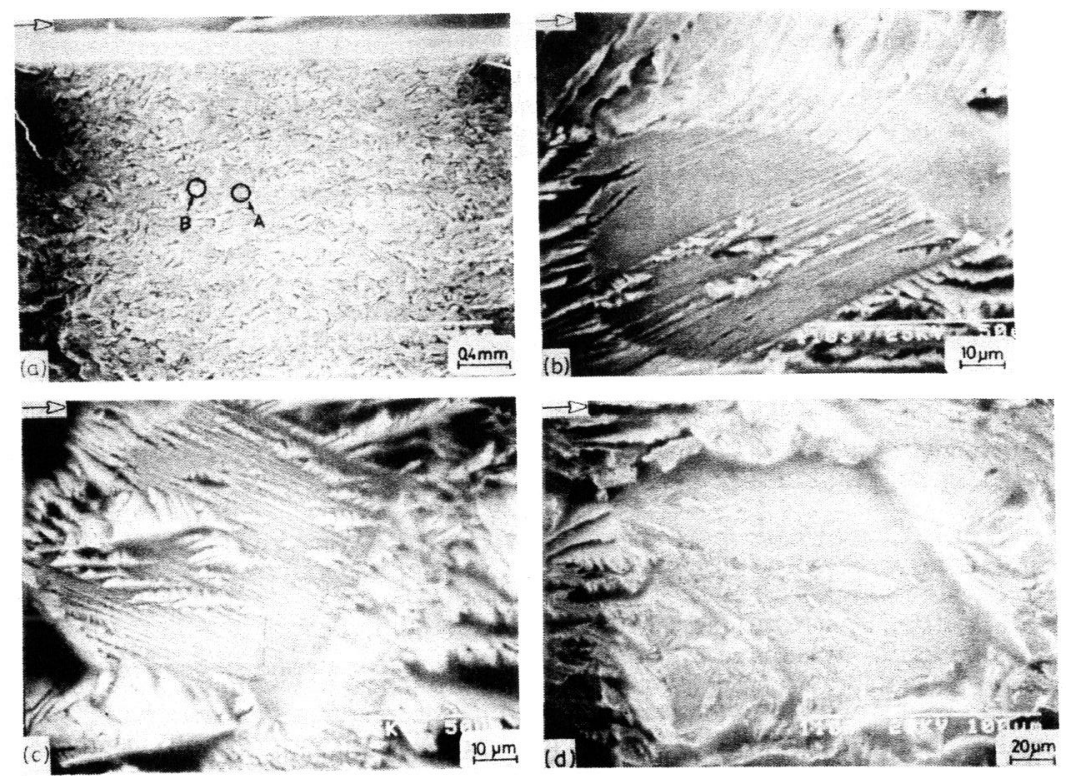

Fig. 8. SEM micrographs of the fracture surface of a specimen tested in air: (a) $\triangle \mathrm{K}=9.55 \mathrm{MPa} \sqrt{\mathrm{m}},(\mathrm{b}, \mathrm{c})$ magnified views of $A$ in air: (a) $\Delta \mathrm{K}=9.55 \mathrm{MPa}$ (d) $\Delta \mathrm{K}=12 \mathrm{MPa} \sqrt{\mathrm{m}}$.

Crack advances in certain microstructures at low $\Delta \mathrm{K}$ take place primarily along a single active slip system Minakawa et al., 1981, Suresh et al., 1984). Such single-shear growth, which occurs primarily when the maximum plastic zone size is typically smaller than the grain size, results in: (a) crystallographic or generally faceted fracture morphology and (c) locally mixed Mode 1 and Il crack gema et al., 1981, Suresh, 1983, Suresh et al., 1984). This of the fatigue cycle, resulting in a fracture surface asperitie during the roughness-induced crack closure. This lion of clip steps (Gray III et al 1983). The present slip material, and enhanced by oxidato or slip steps (Gray int these conditions. The fitgue crack high cra to be mainly due to fracture surface roughness. Flattened regions in SEM micrographs in Fig. 7 and 8-c support this view.

Corrosion products formed within growing cracks can also cause crack closure. Moist Corme frictm within the crack, which further thickens by fretting oxidation (Gray III et al., 1983, Tzou et al., 1985). This mechanism is usually specific to the low $\Delta K$ range, where the oxide thickness is of the order of the crack tip opening displacement. Therefore the debris along the crack observed only in the air at the low $\Delta \mathrm{K}$ in the present study may be the result of fretting oxidation. Slightly higher $\mathrm{P}_{\mathrm{op}} / \mathrm{P}_{\max }$ in air compared to that in silicone oils is thus probably due to the oxide-induced closure. Conditions which may be present at the crack tip for air and oil environments are schematically compared in Fig. 9.

Since the closure load levels were lower in the silicone oils, the effective stress intensity range $\Delta \mathrm{K}_{\text {eff }}$ must be higher, which would give a higher FCGR in oils. But in the present tests at low 


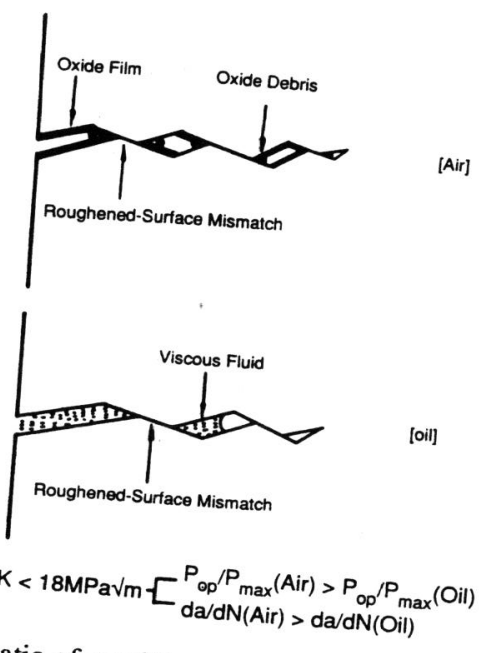

Fig. 9. Schematic of conditions at crack tip for air and silicone oil
environments. crack closure on the FCGR (Gray III et al., 1983) was overshs that the mechanical influence of
the oil at the crack tip. Evidence for the suppression of chemical activity at thelding effect of
silicone oils is provided by the absence of the
for tests in air. in air.

\section{SUMMARY AND CONCLUSIONS}

1. A four-orders of magnitude

detectable effect on the crack closure the viscosity of silicone oil had 2. FCGR in silicor

air at higher $\Delta K$.$$
\text { Mas the }
$$

the fracture surface roughness.

effect on thy lower closure loads in the oils comp

effect on the FCGR.
Shielding from moist air-induced in the oils compared to air had no significant

6. The combined opposite eff for the lower FCGR in silicone oils at the crack tip is environment by the oits effects of a lower closure load oils.

MPa $\sqrt{m}_{\mathrm{m}}$. by the oils yielded a lower FCGR in the oils and shielding from the air

\section{ACKNOWLEDGEMENT}

This research was sponsored by the Department of Energy under Contract DE-FG22-
80PC30236.

REFERENCES
Amzallag C. P. Rabbe, C. Bathias, D. Benoitt and M. Truchon (1981). Influence of Various Parameters on the Determination of the Fatigue Crack Arrest Threshold, ASTM STP 738 , p. 29.

STM Standard E-399 (Plane-Strain Fracture Toughness of Metallic Materials)

ASTM Standard E-647 (Constant-Load-Amplitude Fatigue Crack Growth Rate Above 10-8

m/cycle).
Carter, R.D., E. W. Lee, E. A. Starke and C. J. Beevers (1984). The Effect of Microstructure and Environment on Fatigue Crack Closure of 7475 Aluminum Alloy, Met. Trans. $15 \mathrm{~A}, \mathrm{p} .555$

Endo K. T. Okada and T. Hariya (1972). Fatigue Crack Propagation in Bearing Metals do, K., T. Okada and T. Hurites in Oil, Bull. JSME, Vol. 15, p. 439.

Lining on Steel in Oil Bull. JSME Yol 15, p. 1316

Frost, N. E. (1964) The Effect of Environment on the Propagation of Fatigue Cracks in Mild Steel, Appl. Matls. Res., 3, p. 131.

G. The Effect of Microstructure on Fatigue Crack Path, In: Fatigue Crack Growth Threshold Concepts, p. 131, The Met Soc of AIME.

McCabe, D. E. and J. D. Landes (1980). Design Properties of Steels for Coal Conversion Vessels, Final Rep. EPRI AP-1637, Nov. 1980 (Electric Power Research Inst.) (Research Project 627-1).

Minakawa K. and A. J. McEvily (1981), On Crack Closure in the Near-Threshold Region, Scripta Met., 15, p. 633

Polk, C J., W. R. Murphy and C. N. Rowe (1975). Determining Fatigue Crack Propagation Rates in Lubricating Environments Through the Application of a Fracture Mechanics Technique, ASLE Trans., 18 , p. 290

Ryder, D. A., M. Martin and M. Abdullah (1977). Some Factors Influencing Stage Fatigue-Crack Growth, Metal. Sci., 11, p. 340

Suresh S. and R. O. (1984). Ritchie Propagation of Short Fatigue Cracks, International

Metals Reviews, 29 , p. 445 .
Suresh, S.(1983). Crack Deflection: Implications for the Growth of Long and Short Fatigue Cracks, Met. Trans., 14A, p. 2375.

Suresh, S. and R. O. Ritchie (1983). Near-Threshold Fatigue Crack Propagation: A Perspective on the Role of Crack Closure, In: Fatigue Crack Growth Threshold Concepts, p. 227, The Met. Soc. of AIME

Tzou, J. L., S. Suresh and R. O. Ritchie (1983). Fatigue Crack Propagation in Viscous Environemnts, In: Mech. Behaviour of Materials - IV, (J. Carlsson and N. G. Ohlson, eds. Vol. 2, p. 711 Pergamon Press, NY.

Suresh and R. Ritchie (1985). Fatigue Crack Propagation in Oil Erowth Behavior in Silicone and Paraffin Oils, Acta Met., 33

p. 105.
Tzou, J. L., C. H. Hsueh, A. G. Evans and R. O. Ritchie (1985). Fatigue Crack Propagation in Oil Environments - II. A Model for Crack Closure Induced by Viscous Fluids, Acta Met., $\underline{33}$, p. 117

Vosikovsky O (1976). Fatigue Crack Growth in an X65 Line-Pipe Steel in Sour Crude Oil, Corrosion, 32, p. 472.

Vosikovsky, O and A. Rivard (1982). The Effect of Hydrogen Sulfide in Crude Oil on Fatigue Crack Growth in a Pipe Line Steel, Corrosion, 38, p. 19.

Way, S., J.(1935). Pitting Due to Rolling Contact, Appl. Mech., Trans. ASME Series E, 2

p. A49. Plants (Liquefaction), Annual Rep., Oct. 1, 1980 Sept. 30, 1981 